\title{
Chemical Composition and Insecticidal Activity of Essential Oil from Coriandrum sativum Seeds against Tribolium confusum and Callosobruchus maculatus
}

\begin{abstract}
Abbas Khani and Tahere Rahdari
Department of Plant Protection, Faculty of Agriculture, University of Zabol, P.O. Box 9861335856, Zabol, Iran

Correspondence should be addressed to Abbas Khani, abbkhani@yahoo.com

Received 12 October 2012; Accepted 30 October 2012

Academic Editors: K. Cal, H. Mucke, and M. Y. Rios

Copyright (C) 2012 A. Khani and T. Rahdari. This is an open access article distributed under the Creative Commons Attribution License, which permits unrestricted use, distribution, and reproduction in any medium, provided the original work is properly cited.

The biological activity of essential oil extracted from coriander, Coriandrum sativum L. (Apiaceae), seeds against adults of Tribolium confusum Duval (Coleoptera: Tenebrionidae) and Callosobruchus maculatus F. (Coleoptera: Bruchidae) was investigated in a series of laboratory experiments. Fumigant toxicity was assessed at $27 \pm 1{ }^{\circ} \mathrm{C}$ and $65 \pm 5 \%$ R.H., in dark condition. Dry seeds of the plant were subject to hydrodistillation using a Clevenger-type apparatus. The composition of essential oil was analyzed by gas chromatography mass spectrometry. The predominant components in the oil were linalool (57.57\%) and geranyl acetate (15.09\%). The mortality of 1-7-day-old adults of the insect pests increased with concentration from 43 to $357 \mu \mathrm{L} / \mathrm{L}$ air and with exposure time from 3 to $24 \mathrm{~h}$. In the probit analysis, $\mathrm{LC}_{50}$ values (lethal concentration for $50 \%$ mortality) showed that C. maculatus $\left(\mathrm{LC}_{50}=\right.$ $1.34 \mu \mathrm{L} / \mathrm{L}$ air) was more susceptible than $T$. confusum $\left(\mathrm{LC}_{50}=318.02 \mu \mathrm{L} / \mathrm{L}\right.$ air $)$ to seed essential oil of this plant. The essential oil of $C$. sativum can play an important role in stored grain protection and reduce the risks associated with the use of synthetic insecticides.
\end{abstract}

\section{Introduction}

The global pest-harvest grain losses by insect damage and other bioagents range from $10 \%$ to $40 \%$. Methods used to control stored grain insect pest included physical, chemical, and biological treatments [1]. Chemicals largely used as pesticides in crop protection could have undesirable effects such as ozone depletion, environmental pollution, toxicity to nontarget organism, pest resistance, and pesticide residues, in addition to direct toxicity to users [1]. Therefore, the development of bio insecticides has been focused as viable pest control strategy in recent years $[2,3]$.

Plants may provide potential alternative to currently used insect-control agents because they constitute a rich source of bioactive chemicals [4]. Aromatic plants are among the most efficient insecticides of botanical origin and essential oils often constitute the bioactive fraction of plant extracts [3].

Essential oils are secondary metabolites abundant in aromatic plants families such as Lamiaceae and Apiaceae which contain a large number of compounds such as monoterpens and sesquiterpenes. Essential oils are known to exhibit low toxicity to mammals, and the most terpenoids and phenols found in plant essential oil have minimal toxicity and have even been approved as flavoring agents in food $[2,5]$. The insecticidal $[6,7]$, nematicidal $[8]$, and antibacterial [9] effects of coriander essential oil have previously been reported.

Coriandrum sativum (Apiaceae) is a native of the Mediterranean region and is grown in North Africa, central Europe, and Asia as a culinary herb and medicament. The essential oil of $C$. sativum exhibited volatile toxicity to stored product insects. López et al. [6] fractionated the seeds of Coriander sativum by column chromatography and tested them in the laboratory for volatile toxicity against three stored rice pests, Sitophilus oryzae, Rhyzopertha dominica and Cryptolestes pusillus. Their experiment showed the active compound of coriander essential oil against $S$. oryzae was linalool, while the fractions that contained mixtures of linalool, camphor, and geranyl acetate were as active against 
R. dominica, and C. pusillus as linalool alone. Also the results of Islam et al. [7] showed that the C. sativum essential oil had fumigant toxicity on Tribolium castaneum adults, larvae, and pupae.

The present study was carried out to determine the fumigant toxicity of essential oils extracted from seeds of $C$. sativum against adult stage of two other stored product insects, Tribolium confusum and Callosobruchus maculatus.

\section{Materials and Methods}

Callosobruchus maculatus and Tribolium confusum were reared in plastic containers $(20 \mathrm{~cm}$ length, $14 \mathrm{~cm}$ diameter and $8 \mathrm{~cm}$ height) containing bean grain and wheat flour mixed with yeast $(10: 1, \mathrm{w} / \mathrm{w})$, respectively, which were covered by a fine mesh cloth for ventilation. Adult insects, 17 days old, were used for fumigant toxicity. The culture was maintained in the dark in growth chamber set at $27 \pm 1^{\circ} \mathrm{C}$ and $65 \pm 5$ relative humidity. All experiments were carried out under the same environmental conditions.

Seeds of C. sativum were collected in August, 2009, from Zabol region located in Sistan and Baluchestan province, Iran. The plant material was dried naturally on laboratory benches at room temperature $\left(23-24^{\circ} \mathrm{C}\right)$ for 7 days until crisp. The dried materials were stored at $-24^{\circ} \mathrm{C}$ and then hydrodistilled to extract its essential oil.

Essential oil was extracted from the plant samples using a Clevenger-type apparatus where the plant material is subjected to hydrodistillation. Conditions of extraction were fifty grams of seeds samples, $1: 10$ plant material/water volume ratio, and $4 \mathrm{~h}$ distillation. The C. sativum oil was dehydrated with anhydrous sodium sulphate and stored in airtight glassware in refrigerator at $4^{\circ} \mathrm{C}$ until being used in the treatment.

The essential oil of the Coriandrum sativum seeds was analyzed on a gas chromatograph (Varian suturn 2200) mass spectrometer (varian cp 3800) (GC-mass). The GC column was DB-5 $(30 \mathrm{~m} \times 0.25 \mathrm{~mm}$ i.d, $0.25 \mu \mathrm{m}$ film thickness). The GC conditions were as follows: injector temperature, isothermal at $50^{\circ} \mathrm{C}$ for $1 \mathrm{~min}$, then programmed to $200^{\circ} \mathrm{C}$ at $4^{\circ} \mathrm{C} / \mathrm{min}$. Helium was used as the carried gas at the rate of $0.8 \mathrm{~mL} / \mathrm{min}$. The effluent at the GC column was introduced directly in to the source of the MS. Spectra were obtained in the EI mode with $70 \mathrm{eV}$ ionization energy. The sector mass analyzer was set to scan from 40 to $300 \mathrm{amu}$ for 1s. Unknown essential oil was identified by comparing its GC retention time to that of known compounds and by comparison of its mass spectra, either with known compounds or published spectra.

To determine the fumigant toxicity of the C. sativum oil, filter paper ( $2 \mathrm{~cm}$ diameter) was impregnated with oil at doses calculated to give equivalent fumigant concentration 43-357 $\mu \mathrm{L} / \mathrm{L}$ air. The impregnated filter papers were then attached to the screw tightly caps of glass with volumes of $70 \mathrm{~mL}$. Caps were screwed tightly on the glass, each of which contained separately 10 adults (1-7 days old) of each species of insect. Each concentration and control was replicated four times. Mortality was determined 3 to 24 hours from commencement of exposure in serial time method. When no sign of leg or antennal movement was observed, insect was considered as dead.

Insect mortality percentage in another experiment was designed to assess $50 \%$ lethal doses $\left(\mathrm{LC}_{50}\right)$. A series of dilutions was prepared to evaluate mortality of insect after an initial dose-setting experiment for determination concentrations with about 10 to $90 \%$ mortality. Concentrations of the oil were tested at $0.4,0.8,1.2$, and $2 \mu \mathrm{L} / \mathrm{L}$ air on C. maculatus and evaluated at $92.5,185,278,370$, and $462.5 \mu \mathrm{L} / \mathrm{L}$ air on T. confusum, respectively. Control insects were kept under the same conditions without any essential oil. Each dose was replicated five times. The number of dead and live insects in each bottle was counted $24 \mathrm{~h}$ after initial exposure to the essential oil. The mortality was determined as described in previous experiment. The treatment bottles were monitored for at least $48 \mathrm{~h}$ after recording the data and no affected insect recovered. Data obtained from each dose response bioassay were subjected to probit analysis. $\mathrm{LC}_{50}$ values were estimated by probit analysis using SPSS 16.0.

\section{Results and Discussion}

Chemical composition of essential oil from the seed of coriander, Coriandrum sativum, is given in Table 1. The major components in the essential oil from C. sativum seeds were found: linalool $(57.57 \%)$; geranyl acetate $(15.9 \%) ; \beta$ caryophyllene $(3.26 \%)$, camphor $(3.02 \%)$, and p-cymene $(2.5 \%)$. Chemical analysis indicated clearly that linalool was the main component of coriander essential oil.

The result of our analysis was in agreement with the other literatures that reported linalool as major constituent in the essential oil of coriander $[6,10,11]$. It has been reported that major compounds in the seed coriander oil in Bangladesh were linalool (37.7\%), geranyl acetate (17.6\%), and $\gamma$-terpinene $(14.4 \%)$ [11]. However, the difference in the oil composition was related to the relative proportion of the constituents and not to the presence/absence of a particular component. These variations may be attributed mainly to the plant part, the season (temperature, photoperiod, and hygrometry), the method of harvesting, the geographical zone, pedological condition, and the method used to isolate the plant product [12-14].

In all cases, considerable differences in mortality of insect to essential oil vapor were observed in different concentrations and exposure times. The mortality increased with rising concentrations from 43 to $357 \mu \mathrm{L} / \mathrm{L}$ air and with exposure time from 3 to $24 \mathrm{~h}$.

Results indicated that the oil was relatively more toxic against $C$. maculatus than $T$. confusum (Figure 1). The lowest concentration ( $43 \mu \mathrm{L} / \mathrm{L}$ air) of the oil yielded $100 \%$ mortality of $C$. maculatus after $24 \mathrm{~h}$ exposure but the mortality of $T$. confusum at the same concentration was $25 \%$ after $24 \mathrm{~h}$.

The toxicity of C. sativum oil on C. maculatus and T. confusum was significantly different, as inferred by the confidence intervals of $\mathrm{LC}_{50}$ (Table 2). Probit analysis showed that $C$. maculatus was more susceptible $\left(\mathrm{LC}_{50}=1.34 \mu \mathrm{L} / \mathrm{L}\right.$ air) to C. sativum oil than $T$. confusum $\left(\mathrm{LC}_{50}=318.02 \mu \mathrm{L} / \mathrm{L}\right.$ air) (Table 2). A difference response of the insect species to 
TABle 1: Chemical composition of the essential oil from Coriandrum sativum seeds.

\begin{tabular}{|c|c|c|}
\hline Compounds $\mathrm{s}^{\mathrm{a}}$ & Composition \% & Kovats index \\
\hline Heptanol & 0.78 & 899 \\
\hline$\alpha$-Thujene & 0.19 & 928 \\
\hline$\alpha$-Pinene & 0.12 & 939 \\
\hline Sabinene & 0.58 & 972 \\
\hline$\beta$-Pinene & 0.14 & 979 \\
\hline $1^{3}$-Carene & 0.11 & 1005 \\
\hline$\alpha$-Terpinene & 0.39 & 1010 \\
\hline p-Cymene & 2.52 & 1028 \\
\hline Limonene & 0.62 & 1031 \\
\hline 1,8-Cineol & 0.97 & 1036 \\
\hline (z)- $\beta$-Ocimene & 0.41 & 1040 \\
\hline$\gamma$-Terpinene & 0.11 & 1062 \\
\hline Cis-linalool oxide & 0.07 & 1070 \\
\hline Trans-linalool oxide & 0.83 & 1080 \\
\hline Terpinolene & 0.17 & 1092 \\
\hline Linalool & 57.57 & 1102 \\
\hline$\beta$-Citronella & 0.39 & 1127 \\
\hline Camphor & 3.02 & 1146 \\
\hline Borneol & 1.27 & 1165 \\
\hline Menthol & 0.54 & 1170 \\
\hline Terpinene-4-ol & 0.14 & 1177 \\
\hline p-Cymen-8-ol & 0.29 & 1184 \\
\hline$\alpha$-Terpineol & 0.18 & 1188 \\
\hline Cis-Dihydrocarvone & 0.35 & 1195 \\
\hline Nerol & 1.98 & 1226 \\
\hline Neral & 0.29 & 1237 \\
\hline Carvone & 1.14 & 1242 \\
\hline Geraniol & 0.24 & 1251 \\
\hline Geranial & 1.03 & 1266 \\
\hline Anethole & 0.21 & 1285 \\
\hline Thymol & 0.12 & 1293 \\
\hline Carvacrol & 0.29 & 1300 \\
\hline$\delta$-Elemene & 0.56 & 1340 \\
\hline Eugenol & 0.76 & 1355 \\
\hline Neryle acetate & 0.01 & 1363 \\
\hline Geranyl acetate & 15.09 & 1382 \\
\hline$\beta$-Caryophyellene & 3.26 & 1427 \\
\hline$\alpha$-Humulene & 0.19 & 1454 \\
\hline Germacrene D & 1.01 & 1484 \\
\hline Eugenyle acetate & 0.49 & 1524 \\
\hline Other compounds & 1.60 & - \\
\hline
\end{tabular}

${ }^{a}$ Identification based on authentic standards, NIST library spectra, and literature.

the essential oils has previously been reported for stored product insects [15-17].
The insecticidal property of coriander essential oil was reported in previous studies and its toxicity generally was attributed to linalool $[6,7]$, the volatile compound which was found to be the primary component of seed oil in our chemical analysis. Moreover, the high toxicity of linalool and camphor was reported against stored products pests $[16,18,19]$.

Insecticidal effects of $C$. sativum seed essential oil on adults of Tribolium castaneum and Sitophilus oryzae, Rhyzopertha dominica, and Cryptolestes pusillus have been shown before [6, 7]. Islam et al. [7] reported that fumigant $\mathrm{LC}_{50}$ value of $T$. castaneum at 24 exposure for adults insect was $0.011 \mu \mathrm{g} / \mathrm{mL}$ acetone in glass vials $(25 \times 50 \mathrm{~mm})$ or in other words nearly $448 \mu \mathrm{g} / \mathrm{L}$ air. This value was more than the $\mathrm{LC}_{50}$ value calculated for $T$. confusum species $(318 \mu \mathrm{L} / \mathrm{L}$ air) in our study. More recently, it is shown that the seed oil of the Coriandrum sativum with linalool as major component (55.1\%) has significant toxic effects against the larvae of Aedes aegypti with an $\mathrm{LC}_{50}$ value of $21.5 \mathrm{ppm}$ and could play an important role as immunotoxicity on the insect [20]. The observed difference seems to be reasonable because of different insect species and methodology of oil extraction, as shown in similar experiments with various stored product pests and essential oil vapors [21,22].

Studies on the mode of action of the natural insecticide have shown that treatments the insects with natural compounds such as essential oils or pure compounds may cause symptoms that indicate neurotoxic activity including hyperactivity, seizures, and tremors followed by paralysis (knock down), which are very similar to those produced by the insecticides pyrethroids [23]. It has been recognized that essential oils are potent neurotoxins and could affect through acetyl cholinesterase enzyme inhibition in the central nervous system [24].

Coriander oil and its major constituent, linalool, have low acute oral and dermal toxicity in laboratory animals. The acute lethality studies suggest that the toxicity of the oil is from its constituent, linalool. The acute oral $\mathrm{LD}_{50}$ of the major constituent of coriander oil, linalool, in Osborne Mendel rats was reported to be greater than $2.79 \mathrm{~g} / \mathrm{kg}$ [25]. Collectively, these studies indicate that coriander oil and its major constituent, linalool, are of slight acute toxic potential [26]. As coriander oil contains approximately $70 \%$ linalool, the oral $\mathrm{LD}_{50}$ studies suggest that the lethality caused by the oil is from its constituent, linalool.

\section{Conclusions}

Results of the study show that the essential oil of $C$. sativum seeds can play an important role in stored grain protection and reduce the risks associated with the use of synthetic insecticides. The mode of action of C. sativum oil is of special interest. Further work should focus on its penetration into insect cuticle and grain, metabolic target in the insect body and, its effects on mammals fed on treated material. Therefore essential oil from C. sativum can become an interesting alternative to conventional chemical control strategies. 
TABLE 2: Efficiency of essential oil extracted from Coriandrum sativum seeds against Tribolium confusum and Callosobruchus maculatus.

\begin{tabular}{lcccrr}
\hline Insects & No. $^{*}$ & LC $_{50}(95 \% \mathrm{CL})$ & $\chi^{2}(\mathrm{df})$ & Probability & Slope \pm SE \\
\hline T. confusum & 250 & $318.02(276.96-375.80)$ & $3.93(3)$ & 0.269 & $2.85 \pm 0.41$ \\
C. maculatus & 250 & $1.34(1.12-1.69)$ & $1.80(3)$ & 0.614 & $2.06 \pm 0.36$ \\
\hline
\end{tabular}

${ }^{*}$ Ten individuals per replicate, five replicates per concentration, and five concentrations per assay; LC: lethal concentration ( $\mu \mathrm{L} /$ liter air), CL: confidence limits, $\chi^{2}$ : Chi-square value, df: degrees of freedom.
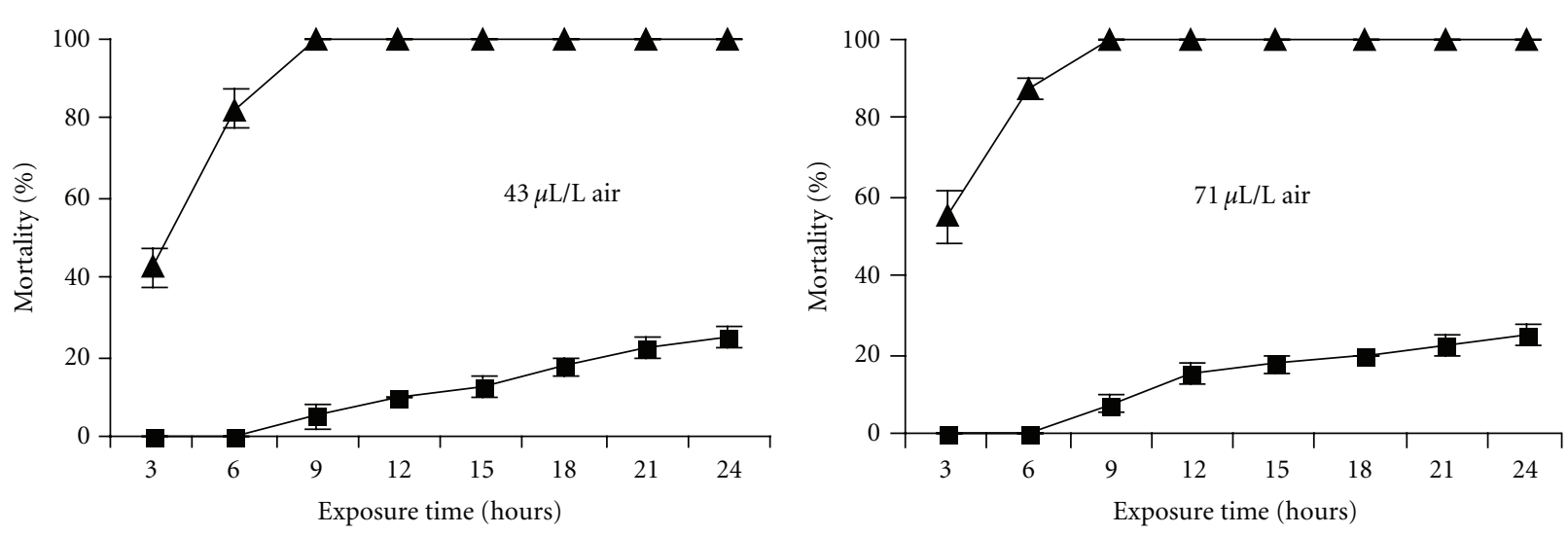

$\rightarrow$ C. maculatus
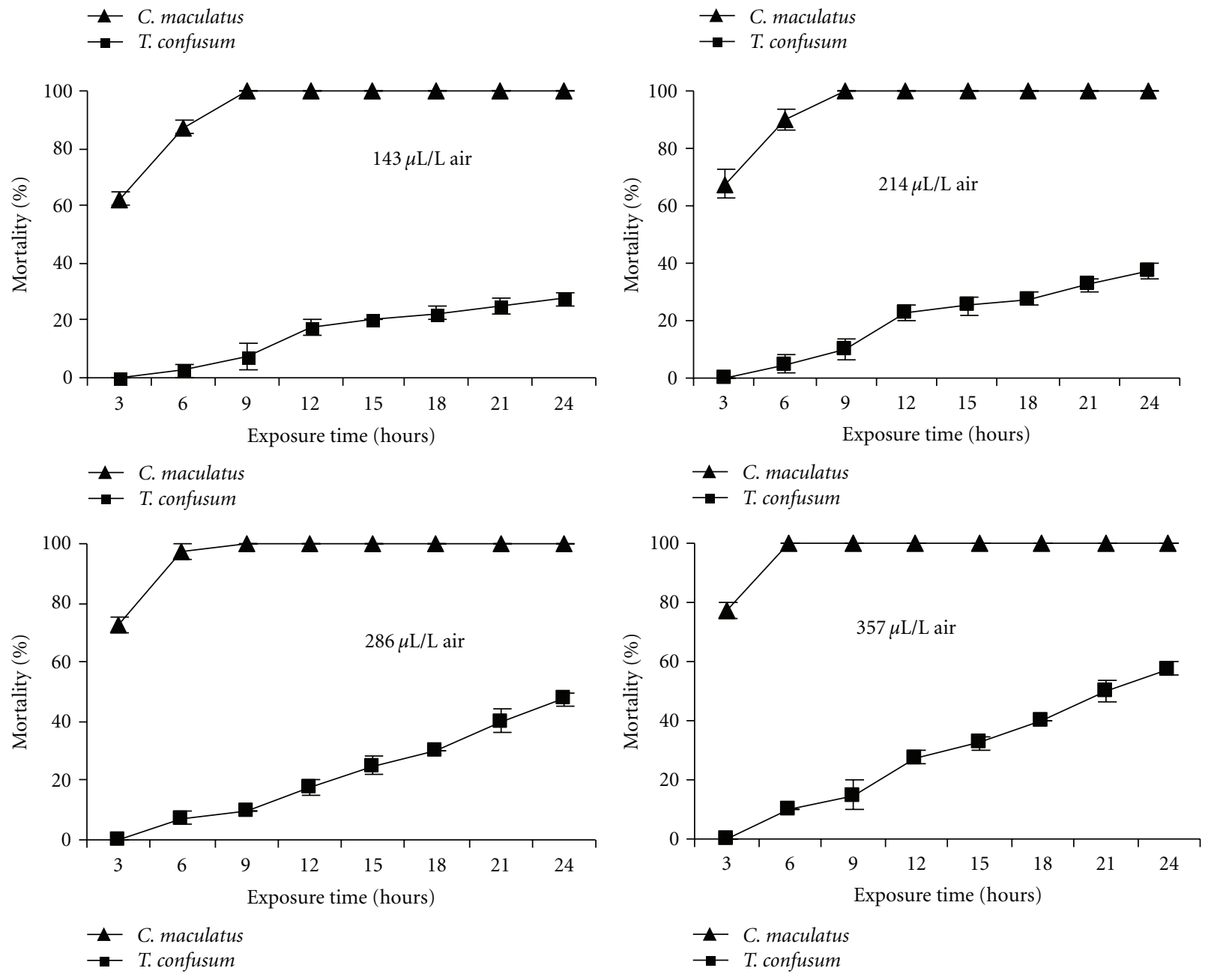

FIGURE 1: Cumulative percentage mortality of Tribolium confusum and Callosobruchus maculatus exposed to various concentrations of essential oils from Coriandrum sativum seeds at various periods of time. 


\section{Acknowledgment}

The research was supported by the University of Zabol, which is greatly appreciated.

\section{References}

[1] M. B. Isman, "Botanical insecticides, deterrents, and repellents in modern agriculture and an increasingly regulated world," Annual Review of Entomology, vol. 51, pp. 45-66, 2006.

[2] M. B. Isman, "Plant essential oils for pest and disease management," Crop Protection, vol. 19, no. 8-10, pp. 603-608, 2000.

[3] E. Shaaya, M. Kostjukovski, J. Eilberg, and C. Sukprakarn, "Plant oils as fumigants and contact insecticides for the control of stored-product insects," Journal of Stored Products Research, vol. 33, no. 1, pp. 7-15, 1997.

[4] S. I. Kim, C. Park, M. H. Ohh, H. C. Cho, and Y. J. Ahn, "Contact and fumigant activities of aromatic plant extracts and essential oils against Lasioderma serricorne (Coleoptera: Anobiidae)," Journal of Stored Products Research, vol. 39, no. 1, pp. 11-19, 2002.

[5] S. Rajendran and V. Sriranjini, "Plant products as fumigants for stored-product insect control," Journal of Stored Products Research, vol. 44, no. 2, pp. 126-135, 2008.

[6] M. D. López, M. J. Jordán, and M. J. Pascual-Villalobos, “Toxic compounds in essential oils of coriander, caraway and basil active against stored rice pests," Journal of Stored Products Research, vol. 44, no. 3, pp. 273-278, 2008.

[7] M. S. Islam, M. M. Hasan, W. Xiong, S. C. Zhang, and C. L. Lei, "Fumigant and repellent activities of essential oil from Coriandrum sativum (L.) (Apiaceae) against red flour beetle Tribolium castaneum (Herbst) (Coleoptera: Tenebrionidae)," Journal of Pest Science, vol. 82, no. 2, pp. 171-177, 2009.

[8] J. Kim, S. M. Seo, S. G. Lee, S. C. Shin, and I. K. Park, "Nematicidal activity of plant essential oils and components from coriander (Coriandrum sativum), oriental sweetgum (Liquidambar orientalis), and valerian (Valeriana wallichii) essential oils against pine wood nematode (Bursaphelenchus xylophilus)," Journal of Agricultural and Food Chemistry, vol. 56, no. 16, pp. 7316-7320, 2008.

[9] I. Kubo, K. I. Fujita, A. Kubo, K. I. Nihei, and T. Ogura, "Antibacterial activity of coriander volatile compounds against Salmonella choleraesuis," Journal of Agricultural and Food Chemistry, vol. 52, no. 11, pp. 3329-3332, 2004.

[10] J. A. Pino, A. Rosado, and V. Fuentes, "Chemical composition of the seed oil of Coriandrum sativum L. from Cuba," Journal of Essential Oil Research, vol. 8, no. 1, pp. 97-98, 1996.

[11] M. N. I. Bhuiyan, J. Begum, and M. Sultana, "Chemical composition of leaf and seed essential oil of Coriandrum sativum L. from Bangladesh," Bangladesh Journal of Pharmacology, vol. 4, no. 2, pp. 150-153, 2009.

[12] T. A. Misharina, "Influence of the duration and conditions of storage on the composition of the essential oil from coriander seeds," Applied Biochemistry and Microbiology, vol. 37, no. 6, pp. 622-628, 2001.

[13] B. M. Smallfield, J. W. van Klink, N. B. Perry, and K. G. Dodds, "Coriander spice oil: effects of fruit crushing and distillation time on yield and composition," Journal of Agricultural and Food Chemistry, vol. 49, no. 1, pp. 118-123, 2001.

[14] A. Gil, E. B. de la Fuente, A. E. Lenardis et al., "Coriander essential oil composition from two genotypes grown in different environmental conditions," Journal of Agricultural and Food Chemistry, vol. 50, no. 10, pp. 2870-2877, 2002.
[15] A. Khani and J. Asghari, "Insecticide activity of essential oils of Mentha longifolia, Pulicaria gnaphalodes and Achillea wilhelmsii against two stored product pests, the flour beetle, Tribolium castaneum and the cowpea weevil, Callosobruchus maculatus," Journal of Insect Science, vol. 12, 2012.

[16] S. Lee, C. J. Peterson, and J. R. Coats, "Fumigation toxicity of monoterpenoids to several stored product insects," Journal of Stored Products Research, vol. 39, no. 1, pp. 77-85, 2002.

[17] M. Negahban, S. Moharramipour, and F. Sefidkon, "Fumigant toxicity of essential oil from Artemisia sieberi Besser against three stored-product insects," Journal of Stored Products Research, vol. 43, no. 2, pp. 123-128, 2007.

[18] V. Rozman, I. Kalinovic, and Z. Korunic, "Toxicity of naturally occurring compounds of Lamiaceae and Lauraceae to three stored-product insects," Journal of Stored Products Research, vol. 43, no. 4, pp. 349-355, 2007.

[19] S. A. M. Abdelgaleil, M. I. E. Mohamed, M. E. I. Badawy, and S. A. A. El-Arami, "Fumigant and contact toxicities of monoterpenes to Sitophilus oryzae (L.) and Tribolium castaneum (Herbst) and their inhibitory effects on acetylcholinesterase activity," Journal of Chemical Ecology, vol. 35, no. 5, pp. 518$525,2009$.

[20] I. M. Chung, A. Ahmad, E. H. Kim et al., "Immunotoxicity activity from the essential oils of coriander (Coriandrum sativum) seeds," Immunopharmacology and Immunotoxicology, vol. 34, no. 3, pp. 499-503, 2012.

[21] Y. Huang, S. L. Lam, and S. H. Ho, "Bioactivities of essential oil from Elletaria cardamomum (L.) Maton. to Sitophilus zeamais Motschulsky and Tribolium castaneum (Herbst)," Journal of Stored Products Research, vol. 36, no. 2, pp. 107-117, 2000.

[22] A. Sanon, M. Garba, J. Auger, and J. Huignard, "Analysis of the insecticidal activity of methylisothiocyanate on Callosobruchus maculatus (F.) (Coleoptera: Bruchidae) and its parasitoid Dinarmus basalis (Rondani) (Hymenoptera: Pteromalidae)," Journal of Stored Products Research, vol. 38, no. 2, pp. 129-138, 2001.

[23] M. Kostyukovsky, A. Rafaeli, C. Gileadi, N. Demchenko, and E. Shaaya, "Activation of octopaminergic receptors by essential oil constituents isolated from aromatic plants: possible mode of action against insect pests," Pest Management Science, vol. 58, no. 11, pp. 1101-1106, 2002.

[24] S. Keane and M. F. Ryan, "Purification, characterisation, and inhibition by monoterpenes of acetylcholinesterase from the waxmoth, Galleria mellonella (L.)," Insect Biochemistry and Molecular Biology, vol. 29, no. 12, pp. 1097-1104, 1999.

[25] P. M. Jenner, E. C. Hagan, J. M. Taylor, E. L. Cook, and O. G. Fitzhugh, "Food flavourings and compounds of related structure I. Acute oral toxicity," Food and Cosmetics Toxicology, vol. 2, pp. 327-343, 1964.

[26] M. J. Derelanko and M. A. Hollinger, "Toxicity classifications," in CRC Handbook of Toxicology, p. 657, CRC Press, Boca Raton, Fla, USA, 1995. 

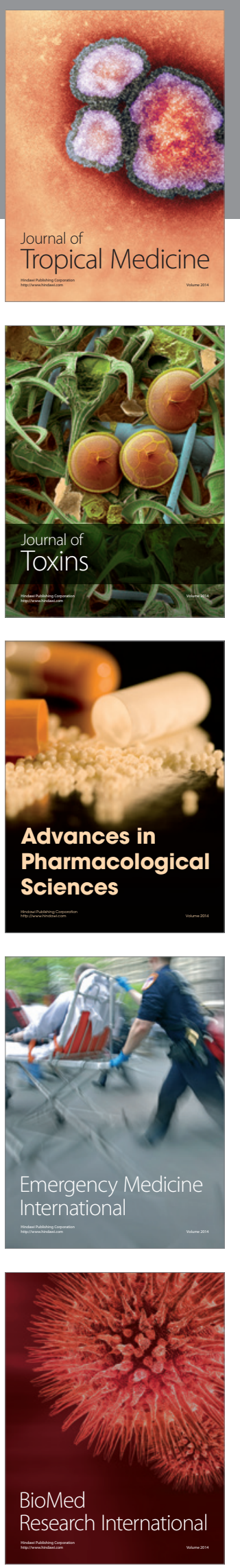
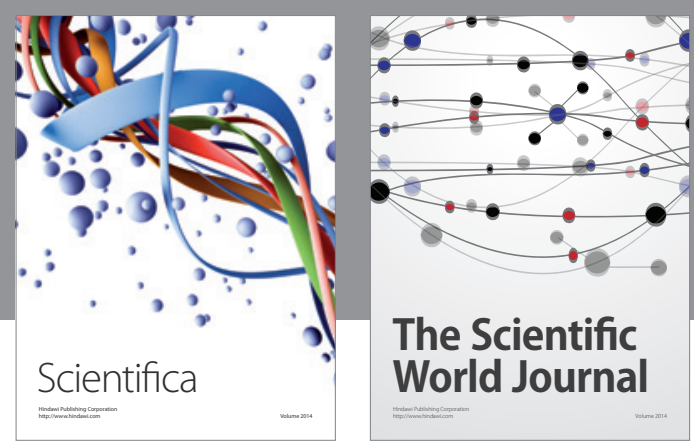

The Scientific World Journal
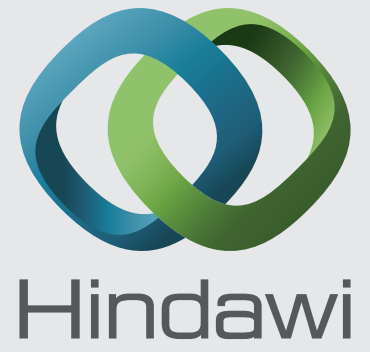

Submit your manuscripts at

http://www.hindawi.com
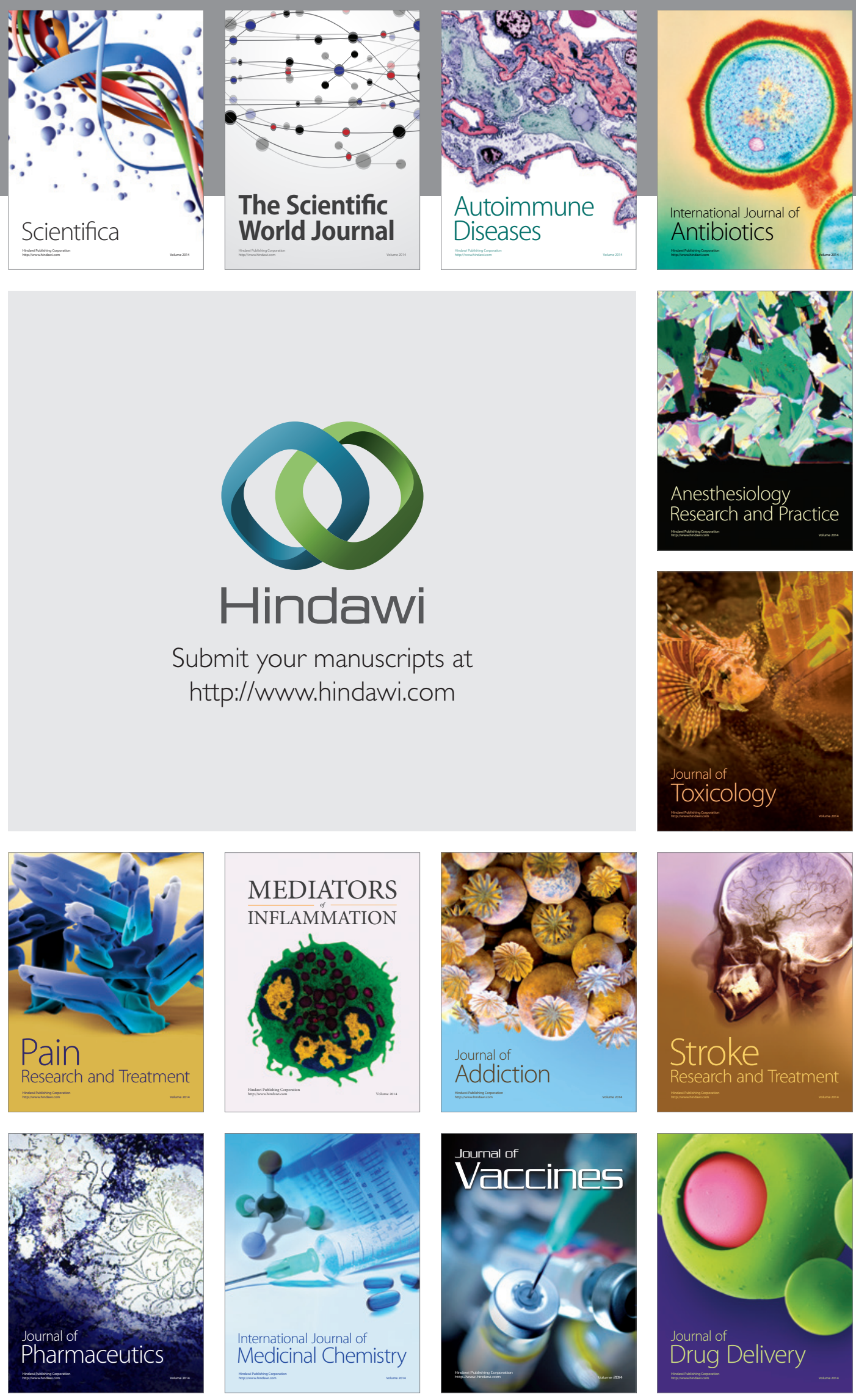